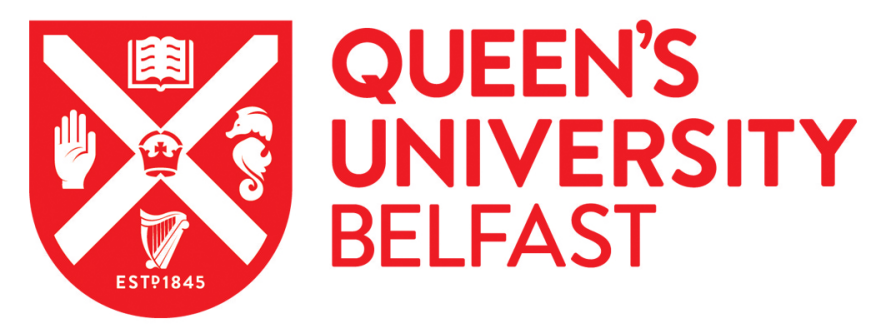

\title{
A randomized controlled trial of a self-management psychosocial intervention for men with prostate cancer and their partners: a study protocol.
}

McCaughan, E., Prue, G., McSorley, O., Northouse, L., Schafenacker, A., \& Parahoo, K. (2013). A randomized controlled trial of a self-management psychosocial intervention for men with prostate cancer and their partners: a study protocol. Journal of Advanced Nursing, 69(11), 2572-2583. https://doi.org/10.1111/jan.12132

Published in:

Journal of Advanced Nursing

Document Version:

Early version, also known as pre-print

Queen's University Belfast - Research Portal:

Link to publication record in Queen's University Belfast Research Portal

\begin{abstract}
Publisher rights
Copyright 2016 The Authors

This is the pre-peer reviewed version of the following article: Mccaughan E., Prue G., Mcsorley O., Northouse L., Schafenacker A. \& Parahoo K. (2013) A randomized controlled trial of a self-management psychosocial intervention for men with prostate cancer and their partners: a study protocol. Journal of Advanced Nursing 69(11), 2572-2583, which has been published in final form at

http://onlinelibrary. wiley.com/doi/10.1111/jan.12132/abstract. This article may be used for non-commercial purposes in accordance with Wiley Terms and Conditions for Self-Archiving.

General rights

Copyright for the publications made accessible via the Queen's University Belfast Research Portal is retained by the author(s) and / or other copyright owners and it is a condition of accessing these publications that users recognise and abide by the legal requirements associated with these rights.
\end{abstract}

\section{Take down policy}

The Research Portal is Queen's institutional repository that provides access to Queen's research output. Every effort has been made to ensure that content in the Research Portal does not infringe any person's rights, or applicable UK laws. If you discover content in the Research Portal that you believe breaches copyright or violates any law, please contact openaccess@qub.ac.uk. 


\begin{abstract}
Background: Little is known about interventions to help men and their partners cope with the after effects of prostate cancer treatment. The lack of in-depth descriptions of the intervention content is hindering the identification of which intervention (or component of an intervention) works.
\end{abstract}

Aim: To describe the development and evaluation of the content of a self-management psychosocial intervention for men with prostate cancer and their partners.

Design: A feasibility randomised controlled trial including structure, process and outcome analysis.

Methods: This nine week intervention commences on completion of treatment and consists of three group and two telephone sessions. The intervention focuses on symptom management, sexual dysfunction, uncertainty management, positive thinking and couple communication. Forty eight couples will be assigned to either the intervention or a control group receiving usual care. Participants will be assessed at baseline, immediately postintervention and at one and six months post-intervention. Outcome measures for patients and caregivers include: self-efficacy, quality of life, symptom distress, uncertainty, benefits of illness, health behaviour and measures of couple communication and support. An additional caregiver assessment will be completed by the partner.

Discussion: The main purpose of this feasibility study is to investigate the acceptability of the CONNECT programme to men with prostate cancer and their partners, and to gain feedback from the participants and facilitators to make changes to and enhance the programme. Reasons why men do not want to participate will be collated to enhance recruitment in the future. We will also test recruitment strategies, randomisation procedures and the acceptability of the questionnaires.

\title{
Keywords:
}

Prostate, cancer nursing, oncology nursing, psychosocial, intervention 


\section{Summary Statement}

\section{What is already known about this topic:}

- There has been an increase in psycho-social interventions for men with prostate cancer in recent years, although many do not include partners.

- There is variation in the content and effect of the interventions for men with prostate cancer and their partners.

- The lack of in-depth descriptions of the content of psycho-social interventions for men with prostate cancer is limiting the ability to determine what type of intervention works.

\section{What this paper adds:}

- A time limited, structured, self-management programme for men with prostate cancer and their partners that is evidence based and meets the current needs of its target population.

- The programme consists of symptom management, sexual dysfunction, uncertainty management, positive thinking and couple communication.

- The programme is delivered in both group and couple telephone sessions.

\section{Implications for practice and/or policy:}

- This protocol provides valuable information on the development and evaluation of the content of a self-management intervention for men with prostate cancer and their partners.

- The techniques to enhance recruitment of men onto a psycho-social intervention programme if successful will aid future practice. 


\section{Introduction}

Prostate cancer accounts for nearly a quarter of all new male cancer diagnoses each year in the United Kingdom (UK) and North America (American Cancer Society 2010, Cancer Research UK 2010). Incidence rates for the disease vary worldwide with the majority of cases diagnosed in economically developed countries, with the highest rates seen in North America, Australia and Northern Europe (American Cancer Society 2010). As the incidence of prostate cancer is rising, there is currently a high prevalence of the disease within the population (Cancer Research UK 2010). In the United States (US), nearly half of all male cancer survivors are prostate cancer survivors (American Cancer Society 2010). Earlier diagnosis, the increased effects of treatment and the increase in life expectancy coupled with the fact that prostate cancer is more prevalent in older men, means that the proportion of men living with the aftermath of prostate cancer diagnosis and treatment will continue to rise for the foreseeable future.

There is a large body of evidence which shows that the diagnosis of prostate cancer brings with it significant psychosocial problems (Lintz et al 2003, Carlson \& Bultz 2004, Namiki et al. 2007, Boonzair et al. 2009). Family, functional, physical and psychological well-being can all be affected (Balderson \& Towell 2003) leading to reduced quality of life (Northouse et al. 2007a). Previous work conducted by the authors demonstrated that the partners of men with prostate cancer were an integral component of the cancer journey (McCaughan et al. 2011). A recent review of the literature on psychosocial adjustment of female partners of men with prostate cancer shows that prostate cancer can have marked repercussions for the partner (Couper et al. 2006). Partners can often be more distressed than the men themselves (Couper et al. 2006), experiencing a lack of information and uncertainty about the future (Mason 2005, Ezer et al. 2011). In another study by Northouse et al. (2007b), spouses reported significantly less self-efficacy and social support than patients. Some couples report concerns about communication, sexuality and intimacy (Sanders et al. 2006, Manne et al. 2010). They may not discuss erectile dysfunction and the loss of sexual intimacy with one another (Boehmer \& Clarke 2001) and can experience different perceptions related to these sexual symptoms (Ezer et al. 2011). Creating an environment that encourages discussion may reduce couple distress and uncertainty and improve their relationship (Manne et al. 2010).

Addressing partners' distress is of particular concern not the least because it has an impact on their own quality of life. The men with prostate cancer depend on them for emotional and 
practical support and for coping and adapting to their illness and its treatment (Manne et al. 2004, McCaughan \& McKenna 2007).

\section{Background}

In a review of randomised controlled trials of psychosocial interventions for prostate cancer patients published in 2005, Weber and Sherwill-Navarro (2005) identified only nine studies since 1970. There has been an increase in recent years with the majority of interventions for men only (Johnson et al. 1988, Davison et al. 1997, Johnson et al. 1997, Wilt et al. 2001, Kim et al. 2002, Rosenberg et al. 2002, Lepore et al. 2003, Bailey et al. 2004, Scura et al. 2004, Templeton \& Coates 2004, Weber et al. 2004, Carmack-Taylor et al. 2006, Zhang et al. 2006, Berglund et al. 2007, Carmack-Taylor et al. 2007, McCorkle et al. 2007, Weber et al. 2007, Zhang et al. 2007, Parker et al. 2009). Two other studies (Mishel et al. 2002, Giesler et al. 2005) were for men but included partners, although only data for patients were reported. Four more intervention studies, one for partners only (Manne et al. 2004) and three involving both patients and partners (Canada et al. 2005, Campbell et al. 2007, Northouse et al. 2007a) were also identified.

The interventions in these studies involved a variety of approaches. The most common was informational (Davison et al. 1997, Wilt et al. 2001, Kim et al. 2002, Lepore et al. 2003, Manne et al. 2004, Templeton \& Coates 2004, Canada et al. 2005, Giesler et al 2005, Berglund et al. 2007, Campbell et al. 2007). Other approaches included cognitive behavioural interventions (Canada et al. 2005, Carmack-Taylor et al. 2006 and 2007, Campbell et al. 2007), uncertainty and stress management (Mishel et al. 2002, Parker et al. 2009), physical training alone or with information (Zhang et al. 2006, Berglund et al. 2007, Zhang et al. 2007) and supportive/educative intervention (Weber et al. 2004, , Giesler et al. 2005, Zhang et al. 2006, McCorkle et al. 2007, Northouse et al. 2007b, Weber et al. 2007, Zhang et al. 2007).

The main outcomes measured in these studies were knowledge gain, quality of life (both general and disease specific), dyadic adjustment, marital satisfaction/communication, anxiety, depression, coping, distress, uncertainty, self-efficacy and health care utilisation. Most studies measured at least two or three of these variables. The findings however showed a mixed picture of benefits and 'no difference' between experimental and control groups. The most beneficial aspect was knowledge gain (Wilt et al. 2001; Lepore et al. 2003; Templeton 
and Coates, 2004). Davison et al. (1997) reported that patients took a more active role in decision making post-intervention, but 'expressive disclosure' had no effect on behavioural, medical, immunological health outcome (Rosenberg et al. 2002). In a study by Kim et al. (2002), the intervention group experienced significantly fewer problems with sleep as a result of receiving audio taped information. There was also a reduction in depression and an increase in self-efficacy (Weber et al. 2005) and less worry (Geisler et al. 2005). Berglund et al. (2007) study however did not show that depression and anxiety were reduced as a result of their psychosocial rehabilitation intervention. In addition, Mishel et al. (2002) failed to show an improvement in uncertainty following the implementation of an uncertainty management intervention.

The findings related to quality of life were also equivocal. Studies by Templeton and Coates (2004) and Geisler et al. (2005) show an increase in quality of life, along with Parker et al. (2009) who demonstrated an improvement in physical quality of life, while those by Lepore et al. (2003), Berglund et al. (2007), Campbell et al. (2007) and Carmack-Taylor (2006) and (2007) did not. Although Lepore et al. (2003) did report an improvement in physical quality of life for men with no college education. Of note are the findings from one study which included both patients and partners. The quality of life of spouses improved significantly, while that of patients did not (Northouse et al. 2007b). The other two studies which reported partner outcomes failed to demonstrate an improvement in caregiver strain or mood (Campbell et al. 2007), or female sexual function (Canada et al. 2005).

While much can be learnt from these studies, there is as yet no firm evidence that specific interventions bring specific outcomes, except that knowledge is increased through educational and informational interventions. There is some evidence that other psychological and social outcomes can be achieved but this is by no means unequivocal. Providing information is crucial but what is required according to Northouse et al (2007b) are interventions which manage uncertainty and increase self-efficacy.

Caution should be exercised when generalising from these studies as they used a variety of interventions and strategies both in terms of content, delivery, duration, outcome measures, sample size and composition. A recent systematic review of interventions for couples concluded that further investigation in the area was warranted (Chambers et al. 2011). This view has been reiterated by Galbraith et al. (2011) who concluded that there is currently a 
paucity of literature determining how best to help couples improve their communication about intimacy, coping strategies, psychosexual functioning and obtaining information on managing long term treatment side effects.

According to Aranda (2008) there is a lack of in-depth descriptions of psychosocial intervention development that is hindering the identification of which interventions (or which components of an intervention) works. The aim of this paper is to describe the development and evaluation of the content of a self-management psycho-social intervention for men with prostate cancer and their partners. 


\section{The study}

\section{Aims and hypotheses}

The Medical Research Council (MRC) (2000) framework for Randomised Controlled Trials of complex interventions has guided the development of the intervention.

The overarching aim of this study is to develop and evaluate the feasibility of a supportive education intervention for men with prostate cancer and their partners. This will be done through an evaluation of the intervention in terms of the three components of the Donabedian's (1978) framework for assessing quality: structure, process and outcome. The success of the intervention will depend on whether it is relevant to the needs of the participants, it achieves the desired outcomes and is financially sustainable. The evaluation will focus on:

1. Structure: To evaluate the cost of implementing the intervention.

2. Process:

a. To explore the perceptions, experience and satisfaction of men with prostate cancer and their partners of taking part in the intervention.

b. To explore the reasons for refusal of men with prostate cancer and their partners who decline to take part in the intervention.

c. To explore the perceptions and experience of facilitators in delivering the intervention.

3. Outcome: to test the effectiveness of the intervention in terms of achieving its proposed outcomes. This will be done by means of a randomised controlled trial (RCT).

\section{Intervention}

A substantial body of work by the authors has contributed to the development of the intervention. Early work by one of the authors (EM) established that men with prostate cancer and their partners have a number of unmet needs (McCaughan \& McKenna 2007a\&b). A large scale mixed methods, longitudinal study built on these early findings. The study showed that post-radiotherapy, men with prostate cancer experience poor quality of life and symptom distress. They want more information on erectile dysfunction and for their partners to be involved in any sexual dysfunction interventions. As such it was concluded that interventions and services should be developed to include the partners of men with prostate 
cancer, not only to help enhance their own role, but to also aid their own coping (McCaughan et al. 2012).

Extensive searches of the literature uncovered an intervention conducted with men with prostate cancer and a family member (FOCUS) (Northouse et al. 2007b). The FOCUS programme was delivered in three home visits over three months with a phone call spaced inbetween visits. Although the programme was acceptable to participants, and had a positive impact on family members (Northouse et al. 2007b), as a result of costly one-to-one visits in the patient's own home, it was not likely to be financially sustainable in the long term (Northouse, personal communication). The current intervention was based on a modified version of the FOCUS study with the aim of making it more appropriate and culturally relevant to men with prostate cancer in Northern Ireland. It was anticipated that the development and adaptation would make the intervention more maintainable in the long term.

The intervention to be evaluated is known as the CONNECT programme. The proposed intervention is designed to improve the participants' belief that they are capable of managing their cancer. It will encourage couples to take a team approach to the management of the illness (Figure 1).

CONNECT is an acrostic with each letter representing a different component of the intervention (Table 1). This 9 week intervention consists of three group meetings (approx. 2 hours per session) on week one, week three and week nine. Men and their partners will also be contacted by telephone on two occasions (week five and week seven). There is evidence to suggest that professional-led groups for people with cancer lead to positive results (Gottlieb \& Wachala 2007). The groups will therefore be facilitated by professionals specifically trained in the CONNECT programme.

During the group sessions, the couples will be invited to participate in facilitator-led discussions on symptom management, sexual dysfunction, uncertainty management and positive thinking. The importance of taking a couple approach to the management of the prostate cancer will be emphasised. These sessions will be supplemented by information material developed specifically for the CONNECT programme. The telephone sessions will be couple led, providing the unique opportunity for the intervention to be individualised as couples are encourage to set their own personal targets in relation to the prostate cancer. 
Group sessions offer the opportunity for dealing with issues of common concern. In the current economic climate they are a cost effective way to support men's needs (CockleHearne \& Faithful 2010). More importantly, however, they have been shown to be a positive experience for those involved (Carmack-Taylor et al. 2006) as men become a source of information and support for each other. However, some men may be reluctant to talk openly about illness and therefore could benefit from the opportunity to talk in private. To effectively address this issue, the one-on-one telephone sessions with each couple were incorporated into the intervention. Studies have shown that men with prostate cancer are willing to discuss psychosocial issues via the telephone (Livingstone et al. 2010), and an improvement in quality of life for men with prostate cancer and their partners has been noted through such an intervention (Badger et al. 2011).

\section{Control group}

The control arm of the study will receive usual care (standard medical follow-up) and thus may avail of the services of the voluntary cancer organisations in Northern Ireland.

\section{Theoretical framework}

The Transactional Model of Stress and Coping (Lazarus and Folkman 1984) is a framework for evaluating the processes of coping with stressful events. When people are faced with a threat, they appraise the threat in terms of how challenging or controllable it is (primary appraisal). They also appraise their own and external resources at their disposal to face the threat (secondary appraisal). How they eventually cope depends on these appraisals. If the disease is seen as overwhelming and their own and external resources inadequate, they may feel incapable of coping.

A model based on the Theory of Self-Efficacy (Bandura 1997) and the Theory of Stress and Coping (Lazarus \& Folkman 1984) is proposed to underpin the intervention. The provision of information and the development of self-management skills will help the men and partners appraise their illness as well as their own and external resources, and cope with their problems effectively. This will lead to less distress and prevent marital conflicts, thereby contributing to their overall quality of life.

\section{Sample}


The first stage of the programme of work (McCaughan et al. 2011) identified the period immediately following treatment as a time of isolation, where men with prostate cancer experienced a lack of information and support. The couples for the CONNECT programme will therefore be recruited within six months of completing treatment to capitalise on this teachable moment (McBride et al. 2008). This will also ensure that the couples in the groups will be at the same post-treatment stage, and therefore should have similar needs. Recruiting men with different needs has been suggested to affect adherence, promote attrition and dilute intervention effect (Cockle-Hearne \& Faithful 2010).

Men with prostate cancer will be recruited from the regional Cancer Centre. The inclusion criteria are men aged 18 years and over, diagnosed with localised adenocarcinoma of the prostate, post-surgical or radiation treatment (curative intent) with or without hormone treatment who are able to participate and provide fully informed written consent. The men will also be required to have a spouse or cohabiting partner. Couples will be excluded if the spouse/partner had been diagnosed with cancer within the past year.

\section{Randomisation procedures}

The design of the RCT component of the study has been guided by the CONSORT statement (Moher et al. 2001). Couples will be randomly assigned to the intervention or control group using a randomised block design. The population will be divided into homogenous subgroups (or blocks) in accordance with geographical location (eight couples in each geographical location, giving four couples in each intervention arm). Following division, the participants will be randomly assigned to either the intervention or the control group using randomisation occurring in blocks of eight, with treatment and control occurring four times within each block. Block randomisation will ensure equal numbers in both treatment and control groups, but will also aid allocation concealment and reduce selection bias as randomisation will occur after recruitment. As this is a feasibility study a sample size calculation is not appropriate, however it is anticipated that there will be six intervention cohorts, each comprising 4 men and their partners (a total of 24 couples). Equivalent numbers will be randomly assigned to the control arm, giving a total of 48 men and their partners.

\section{$\underline{\text { Data collection }}$}

Data will be collected from both men and their partners at 4 time-points: prior to the intervention, immediately post-intervention, one month and 6 months post-intervention. The 
assessment at six months is to determine the longer term effect of the intervention. For those in the control group data will be collected at the equivalent time-points (Figure 2).

The main focus of the CONNECT programme is to improve the participants' belief that they are capable of managing their (or their partner's) cancer. The intervention will assist in the development of the skills needed to effectively take care of themselves, and increase their belief that they possess these skills. The primary outcome will therefore be self-efficacy, measured using a modified version of the Lewis Cancer Self-Efficacy Scale (CASE) (Lewis 1996). This original Likert-type scale was modified to a 17 -item scale which has been used previously in the FOCUS study (Northouse et al. 2007b) and in other studies of individuals with breast cancer and their family members (Northouse et al. 2002). The internal consistency alpha coefficient of the original scale was .97 and evidence of content and criterion validity has been reported (Lewis 1996).

Quality of life will be measured by the Functional Assessment of Cancer Therapy (FACT-G) [68]. Esper and colleagues (1997) developed a prostate cancer subscale for use with the FACT-G. The FACT-P consists of 12 items related to sexuality, bowel/bladder function and pain (Esper et al. 1997). Adequate internal consistency, concurrent validity and sensitivity have been reported (Esper et al. 1997).

Symptom distress will be measured with the 16- item Symptom Scale of the Omeaga Screening Questionnaire (OSQ) (Mood \& Bickes 1989). Evidence of concurrent validity, internal consistency, and test-retest reliability of the scale has been reported (Mood and Bickes, 1989; Mood et al., 1995).

Communication about the illness (between men and their partner) will be measured by the Lewis Mutuality and Interpersonal (MIS) Scale (Lewis 1996). The MIS has shown reasonable internal consistency (alpha coefficient .85 - .88) in a sample of caregivers (Siefert et al. 2008).

Uncertainty surrounding the cancer experience will be measured using a modified Mishel Uncertainty in Illness Scale (Mishel \& Epstein 1990) as used in the FOCUS study (Northouse et al 2007b). Adequate internal consistency and construct validity of the original scales has been reported for both patients and family members (Mishel \& Epstein 1990). 
A modified Helgeson Benefits of Illness Scale will be used to quantify any positive aspects respondents associate with the cancer experience. Respondents rate the extent to which the attitudes and behaviours had changed as a result of their illness experience (Helgeson et al., 2004, Tomich and Helgeson, 2004). The complete scale has shown an internal consistency of .95 (Helgeson et al., 2004).

Two other scales used in FOCUS study, the Support Scale and the Health Behaviours Scale will also be used in the current study.

The impact of the illness on the partner will be measured using the Caregiver Assessment Scale, a modified version of the longer Caregiver Reaction Assessment Scale (Given et al. 1992). Internal consistency reliability ranging from .70 to .85 for each subscale has been reported in a study of caregivers (Siefert et al., 2008).

\section{Ethical considerations}

Ethical approval has been granted from the university and regional office of Research Ethics Committees (December 2011). The autonomy of participants is central to this investigation. Participants will be made aware that their consent is fluid and that they have the right to withdraw at any time. The principle of justice refers to equal share and fairness. One of the crucial and distinctive features of this principle is avoiding exploitation and abuse of participants. This will be adhered to in this study by ensuring all potential participants have all of the necessary information for informed consent and had the opportunity to ask questions about the study. Written consent will be obtained without any coercion of study participants. Confidentiality will be assured and participants will be made aware that any digital recordings will be deleted following transcription. All information pertaining to individuals will be anonymised from the outset of the study and consent sought for the use of anonymised quotes from participants.

\section{Data Analysis}

\section{Structure evaluation}

Detailed accounts of the hours spent by staff conducting the intervention will be kept. These will be converted into costs according to their salaries. The cost of materials (booklets and other aids), and of training counsellors and room hire will be recorded. 


\section{Process evaluation}

The process evaluation will consist of three parts a) the perceptions and experience of the men and their partners of taking part in the intervention and b) the perceptions of the men and their partners who declined to take part and c) the perceptions and experience of facilitators in delivering the intervention. A questionnaire similar to that developed by Cimprich et al. (2005) to evaluate the process of her intervention for breast cancer patients will be used to evaluate the perceptions of the participants. This short questionnaire includes items related to self-management activities, programme content, format, duration and delivery and items related to usefulness, relevance and timeliness of the intervention. All participants (men and their partners) who take part in the intervention will be asked to rate items on a Likert-type scale at the end of the intervention. These quantitative data will be explored further in semistructured interviews with 10-15 participants and their partners who will also have the opportunity to discuss what the intervention means for them. The men and their partners will be interviewed separately to reduce the possibility of an individual not disclosing a personal issue they have with the programme in front of their partner. The second aim will be explored through semi-structured interviews with the couples who decide not to take part. They will be asked whether or not they would be willing to be interviewed on their decision. The facilitators’ experience will be explored through semi-structured interviews.

Data from interviews will be tape-recorded, transcribed and analysed with the use of N-Vivo software. As usual with qualitative analysis, transcripts will be read for codes, categories and themes.

\section{Outcome evaluation}

The outcome of the RCT will be analysed on an intention-to-treat basis. Data will be analysed using the SPSS statistical software package. The number of men screened, those eligible and ineligible, those accrued and those not willing to participate with reasons for ineligibility and non-participation will be documented. This data will be examined and descriptive analysis carried out to identify any differences between participants and non-participants. Demographic and clinical data of participants will be summarised using descriptive statistics. Possible differences in demographic characteristics between treatment and control groups will be evaluated using chi square analysis and t-test for continuous variables. A two way (group x time) repeated measures analysis of variance will be carried out to determine the differences, if any, in the two groups over time. A p value of 0.05 will be applied as the 
criterion for statistical significance. Due to the relatively small numbers of participants it is unlikely that statistically significant differences will be identified however, it may be possible to identify clinically meaningful change. In relation to quality of life, the change scores for the FACT-P questionnaire can be calculated for each man with prostate cancer and categorized according to pre-established minimally important differences (MIDs) (Yost \& Eton 2005). Between group comparisons can then be carried out on the categorized scores using Chi-square and student $\mathrm{t}$ tests where appropriate.

\section{Discussion}

It is well documented that men are low users of cancer information and support services. They do not typically acknowledge illness or openly discuss concerns with other men in a public setting (Arrington et al. 2005, Oliffe et al. 2009). To address this, to optimise recruitment and retention, a gender sensitive, 'male friendly framework’ (Peate, 2011) was used. There were two strands to the 'male friendly' approach 1) the design and delivery of the CONNECT programme and 2) methods of recruitment.

\section{Programme design and delivery}

The programme has been created to be a structured, time limited intervention focusing on specific topics (identified as important by men with prostate cancer) (McCaughan et al. 2011). The participants will be informed of what is being delivered each week (Table 2) to give the impression of 'information sessions' as opposed to general discussion 'support groups' as suggested by Bell et al (2010). This tight organised structure is to ensure the intervention is not viewed as an on-going psychological support group more favoured by women (Bell et al. 2010). In addition, the name of the intervention and the terminology used in participant information was carefully considered, and does not refer to the intervention as a support group (Seymour Smith 2008). The telephone sessions should appeal to men as the time to discuss more individual issues. The information sheets to be used during the group sessions are designed to be male friendly (i.e. brief, factual and informative (British Medical Association 2011)) and will be made available to download by the men in their homes should they not wish to acknowledge their need for the information in the group setting.

\section{Methods of recruitment}

Getting men to attend the group sessions will be one of the most challenging aspects of the study. However, previous research into male cancer support groups has suggested that men in 
self-help groups legitimise their attendance by constructing themselves as offering help or giving advice (Davison et al. 2008, Seymour Smith 2008, McCaughan et al. 2012).Therefore, the study will adopt recruitment strategies that appeal to these hegemonic masculine ideals, for example, by asking potential participants for their help and advice in the development of an intervention for men with prostate cancer.

In accordance with Bellg et al (2004), steps were undertaken to ensure intervention fidelity. To ensure each participant receives the same dose, the intervention length was fixed with a set number of group and telephone sessions. A programme manual was developed which includes precise detail of the content of each session. The facilitators will be required to complete an intervention diary after each session to record any deviations from the programme. Before delivering the intervention, facilitators will undertake a week long training programme during which they will familiarise themselves with the CONNECT programme and their role within it. The importance of adherence to rigour will also be emphasised.

\section{Conclusion}

This paper describes the development and proposed evaluation of a self-management psychosocial intervention for men with prostate cancer and their partners. To maximise effectiveness and relevance to the target population, the intervention was developed based on current literature, the views of men with prostate cancer in Northern Ireland, and expert opinion. As the partners of men with prostate cancer are often overlooked, despite being a vital part of the prostate cancer experience, it was decided to make them a main focus of the intervention, alongside the individual with prostate cancer. This is in line with the needs of men with prostate cancer in Northern Ireland (McCaughan et al. 2011). In an attempt to ensure that the intervention appealed to men, a 'male friendly framework' guided study development. The CONNECT programme is a structured, time limited (9 week) intervention, to facilitate men and their partners to become effective self-managers, with the aim of enhancing their quality of life and of reducing their need to access health care services.

The intervention is needed as there is currently limited service provision in Northern Ireland for men with prostate cancer who have completed treatment, and their partners but are still experiencing psychological and/or physical symptoms. Currently there is no provision in the form of interventions designed specifically to address the support needs of this population. 


\section{References}

American Cancer Society (2010) Cancer Facts and Figures. Atlanta American Cancer Society.

Aranda S. (2008) Designing nursing interventions. Collegian: Journal of the Royal college of Nursing Australia 15: 19-25.

Arrington M.I., Grant C.H., Vanderford M.L. (2005) Man to man and side by side, they cope with prostate cancer: self-help and social support. Journal of Psychosocial Oncology 23: 81102.

Badger T.A., Segrin C., Figueredo A.J., Harrington J., Sheppard K., Passalacqua S., Pasvogel A., Bishop M. (2011) Psychosocial interventions to improve quality of life in prostate cancer survivors and their intimate or family partners. Quality of Life Research 20: 833-844.

Bailey D.E., Mishel M.H., Belyea M., Stewart J.L., Mohler J. (2004) Uncertainty intervention for watchful waiting in prostate cancer. Cancer Nursing 27: 339-346.

Balderson N., Towell T. (2003) The prevalence and predictors of psychological distress in men with prostate cancer who are seeking support. British Journal of Health Psychology 8: 125-134.

Bandura A. (199) Self efficacy: The exercise of control. New York: Freeman.

Bell K., Lee J., Foran S., Kwong S., Christopherson J. (2010) Is there an 'ideal cancer' support group? Key findings from a qualitative study of three groups. Journal of Psychosocial Oncology 28: 432-449.

Bellg A.J., Resnick B., Minicucci D.S., Ogedegbe G., Ernst D., Borrelli B., Hecht J., Ory M., Orwig D., Czajkowski S. (2004) Enhancing treatment fidelity in health behaviour change studies: best practices and recommendations from the NIH behaviour change consortium. Health Psychology 23: 443-451.

Berglund G., Pelersson L.M., Eriksson K., Wallenius I., Roshanai A., Nordin K.M., Sjoden P.O., Haggman M. (2007) "Between Men”: A psychosocial rehabilitation programme for me with prostate cancer. Acta Oncologica 46: 83-89.

Boehmer U., Clarke J.A. (2001) Communication about prostate cancer between men and their wives. Journal of Family Practice 50: 226-231.

Boonzair A., Schubach K., Troup K., Pollard A., Aranda S., Schofield P. (2009) Development of a psychoeducational intervention for men with prostate cancer. Journal of Psychosocial Oncology 27: 136-153.

British Medical Association Northern Ireland. (2011) Improving men's health in Northern Ireland. British Medical Association Northern Ireland.

Campbell L.C., Keefe F.J., Scipio C., McKee D.C., Edwards C.L., Herman S.H., Johnson L.E., Colvin M., McBride C.M., Donatucci C. (2007) Facilitating research participation and 
improving quality of life for African American prostate cancer survivors and their intimate partners: a pilot study of telephone-based coping skills training. Cancer 109: 414-424.

Canada A.L., Neese L.E., Sui D., Schover L.R. (2005) Pilot intervention to enhance sexual rehabilitation for couples after treatment for localised prostate carcinoma. Cancer 104: 26892700 .

Cancer Research UK (2010) Prostate Cancer Survival Statistics. Cancer Research UK http://info.cancerresearchuk.org/cancerstats/types/prostate/survival/

Carlson L.E., Bultz B.D. (2004) Cancer distress screening: Needs, models and methods. Journal of Psychosomatic Research 55: 4403-409.

Carmack-Taylor C.L., de Moor C., Basen-Engquist K., Smith M.A., Dunn A.L., Badr H., Pettaway C., Gritz E.R. (2007) Moderator analyses of participants in the active for life after cancer trial: implications for physical activity group intervention studies. Annals of Behavioural Medicine 33: 99-104.

Carmack-Taylor C.L., Demoor C., Smith M.A., Dunn A.L., Basen-Engquist K., Nielsen I., Pettaway C., Sellin R., Massey P., Gritz E.R. (2006) Active for life after cancer: a randomized trial examining a lifestyle physical activity program for prostate cancer patients. Psycho-oncology 15: 847-862.

Cella D.F., Tulsky D.S., Gray G., Sarafian B., Linn E., Bonomi A., Silberman M., Yellen S.B., Winicour P., Brannon J. (1993) The Functional Assessment of Cancer Therapy (FACT) scale: development and validation of the general measure. Journal of Clinical Oncology 3: $570-579$.

Chambers S.K., Pinnock C., Lepore S.J., Hughes S., O’Connell D.L. (2011) A systematic review of psychosocial interventions for men with prostate cancer and their partners. Patient Education and Counselling 85: 75 - 88.

Cimprich B., Janz N.K., Northhouse L., Wren P.A., Given B., Given C.W. (2005) Taking Charge: A self-management program for women following breast cancer treatment. PsychoOncology 14: 704-17.

Cockle-Hearne J., Faithfull S. (2010) Self-management for men surviving prostate cancer: a review of behavioural and psychosocial interventions to understand what strategies can work, for whom and in what circumstances. Psycho-Oncology 19: 909-922.

Couper J., Bloch S., Love A., Macvean M., Duchesne G.M., Kissane D. (2006) Psychosocial adjustment of female partners of men with prostate cancer. Psycho-Oncology 15: 937-953.

Davison B., Joyce R.N., Degner L.F. (1997) Empowerment of men newly diagnosed with prostate cancer. Cancer 20: 187-196.

Davison B.J., So A., Goldenberg S.L., Berkowitz J., Gleave M.E. (2008) Measurement of factors influencing the participation of patients with prostate cancer in clinical trials: a Canadian perspective. British Journal Urology 101: 982 - 987. 
Donabedian A. (1978) The quality of medical care. Science 200: 856-864.

Esper P., Fei M.O., Chodak G., Sinner M., Cella D., Pienta K.J. (1997) Measuring quality of life in men with prostate cancer using the functional assessment of cancer therapy - prostate instrument. Urology 50: 920-928.

Ezer H., Rigol Chachamovich J.L., Chachamovich E. (2011) Do men and their wives see it the same way? Congruence within couples during the first year of prostate cancer. PsychoOncology 20: 155-164.

Galbraith M.E., Fink R., Wilkins G.G. (2011) Couples surviving prostate cancer: challenges in their lives and relationships. Seminars in Oncology Nursing 27: 300-308.

Giesler R.B., Given B., Given C., Rawl S., Monahan P., Burns D., Azzouz F.M., Reuille K.M., Weinrich S., Koch M., Champion V. (2005) Improving the quality of life of patients with prostate carcinoma. Cancer 104: 752-62.

Given C.W., Given B., Stommel M., Collins C., King S., Franklin S. (1992) The caregiver reaction assessment (CRA) for caregivers to persons with chronic physical and mental impairments. Research in Nursing and Health 15: 271 - 283.

Gottlieb B.H., Wachala D. (2007) Cancer support groups: a critical review of empirical studies. Psycho-Oncology 16: 379-400.

Hegleson V.S., Snyder P., Seltman H. (2004) Psychological and physical adjustment to breast cancer over four years: identifying distinct trajectories of change. Health Psychology 23: 315.

Johnson J.E., Fieler V.K., Wlasowicz G.S., Mitchell M.L., Jones L.S. (1997) The effects of nursing care guided by self-regulation theory on coping with radiation therapy Oncology Nursing Forum 24: 1041-50.

Johnson J.E., Nail L.M., Lauver D., King K.B., Keys H. (1988) Reducing the negative impact of radiation therapy on functional status. Cancer 61: 46-81.

Kim U., Roscoe J.A., Morrow G.R. (2002) The effects of information and negative affect on severity of side effects from radiation therapy for prostate cancer. Support Care in Cancer 10: $416-21$.

Lazarus R.S., Folkman S. (1984) Stress, Appraisal and Coping. Springer: New York.

Lepore S., Helgeson V., Eton D., Schulz R. (2003) Improving quality of life in men with prostate cancer: a randomized controlled trial of group education interventions. Health Psychology 22: 443-452.

Lewis FM. (1996) Family home visitation study final report. Bethesda, Md: National Cancer Institute. NIH. 
Lintz K., Moynihan C., Steginga S., Norman A., Eeles R., Huddart R., Dearnaley D., Watson M. (2003) Prostate cancer patients' support and psychological care needs: survey from a nonsurgical oncology clinic. Psycho-Oncology 12: 769-783.

Livingstone P.M., White V.M., Hayman J., Maunsell E., Dunn S.M., Hill D. (2010) The psychological impact of a specialist referral and telephone intervention on male cancer patients: a randomised controlled trial. Psycho-Oncology 19: 617-625.

Manne S., Babb J., Pinover W., Horwitz E., Ebbert J. (2004) Psychoeducational group intervention for wives of men with prostate cancer. Psycho-Oncology 13: 37-46.

Manne S., Badr H., Zaider T., Nelson C., Kissane D. (2010) Cancer-related communication, relationship intimacy, and psychological distress among couples coping with localised prostate cancer. Journal of Cancer Survivorship 4:74-85.

Mason T.M. (2005) Information needs of wives of men following prostatectomy. Oncology Nursing Forum 32: 557-563.

McBride C., Puelo E., Pollack K.I., Clipp E.C., Wodford S., Emmons K.M. (2008) Understanding the role of cancer worry in creating a teachable moment for multiple risk factor reduction. Social Science and Medicine 66: 790 - 800.

McCaughan E., McKenna H. (2007) Information-seeking behaviour of men newly diagnosed with cancer: a qualitative study. Journal of Clinical Nursing 16: 2105 -2113.

McCaughan E., McKenna H. (2007) Never-ending making sense: towards a substantive theory of the information-seeking behaviour of newly diagnosed cancer patients. Journal of Clinical Nursing 16: 2096-2107.

McCaughan E., McSorley O., Prue G., Parahoo K., Bunting B., O’Sullivan J., McKenna H. (2012) Quality of life and side-effects experienced in men receiving radiotherapy and neoadjuvant androgen deprivation for prostate cancer: results from a prospective longitudinal study. Journal of Advanced Nursing (epub ahead of print).

McCaughan E., McSorley O., Prue, G., Parahoo K., O’Sullivan J., Bunting B., McKenna H. (2011) The experience and coping behaviours of men with prostate cancer receiving combined radiotherapy and hormone treatment. Report, University of Ulster.

McCaughan E., Prue G., Parahoo K. (2012) Exploring and comparing the experience and coping behaviour of men and women with colorectal cancer after chemotherapy treatment: a qualitative longitudinal study. Psycho-oncology 21: 64-71.

McCorkle R., Siefert M.L., Dowd M.F., Robinson J.P., Pickett M. (2007) Effects of advanced practice nursing on patient and spouse depressive symptoms, sexual function, and marital interaction after radical prostatectomy. Urology Nursing 27: 65-77.

Medical Research Council. (2000) A framework for development and evaluation of RCTs for complex interventions to improve health. London: $M R C$. 
Mishel M., Belyea M., Germino B., Stewart J., Bailey D., Robertson C., Mohler J. (2002) Helping patients with localized prostate carcinoma manage uncertainity and treatment side effects: nurse delivered psychoeducational intervention over the telephone. Cancer 94: 18541866.

Mishel M., Epstein D. (1990) Uncertainty in illness scales: manual. Tucson, AZ, University of Arizona.

Moher D., Schulz K.F., Altman D.G. (2001) The CONSORT statement: revised recommendations for improving the quality of reports of parallel group randomised trials. BMC Medical Research Methodology 1: 2.

Mood D., Bickes J. (1989) Strategies to enhance self-care in radiation therapy. Oncology Nursing Forum 16(suppl): 43.

Mood D., Northouse L., Oberst M. (1995) Psychosocial interventions in radiation therapy. Bethseda MD, NCI.

Namiki S., Saito S., Tochigi T., Numata I., Ioritani N., Arai Y. (2007) Psychological distress in Japanese men with localized prostate cancer. International Journal of Urology 14: 924929.

Northouse L.L., Mood D., Kershaw T., Schafenacker A., Mellon S., Walker J., Galvin E., Decker V. (2002) Quality of life of women with recurrent breast cancer and their family members. Journal of Clinical Oncology 20: 4050 - 4064.

Northouse L., Mood D., Montie J., Sandler H., Forman D., Hussain M., Pienta J., Smith D., Sanda M., Kershaw T. (2007a) Living with prostate cancer: patients' and spouses; psychosocial status and quality of life. Journal of Clinical Oncology 25: 4171-4177.

Northouse L.L., Mood D.W., Schafenacker A., Montie J.E., Sandler H.M., Forman J.D., Hussain M., Pienta K.J., Smith D.C., Kershaw T. (2007b) Randomized clinical trial of a family intervention for prostate cancer patients and their spouses. Cancer 110: 2809 - 2818.

Oliffe J.L., Ogrodniczuk J., Bottorff J.L., Hislop T.G., Halpin M. (2009) Connecting humour, health, and masculinities at prostate cancer support groups. Psycho-oncology 18: 916-926.

Parker P.A., Pettaway C.A., Babaian R.J., Pisters L.L., Miles B., Fortier A., Wei Q., Carr D.D., Cohen L. (2009) The effects of a presurgical stress management intervention for men with prostate cancer undergoing radical prostatectomy. Journal of Clinical Oncology 27: 3169-3176.

Peate I. (2011) Men and cancer: the gender dimension. British Journal of Nursing 20: 340343.

Rosenberg H., Rosenberg S., Ernstoff M. (2002) Expressive disclosure and health outcomes in a prostate cancer population. International Journal of Psychiatry in Medicine 32: 1 
Sanders S., Pedro L., Bantum E., Galbraith M.E. (2006) Couples surviving prostate cancer: long term intimacy needs and concerns following treatment. Clinical Journal of Oncology Nursing 10: 503-508.

Scura K.W., Budin W., Garfing E. (2004) Telephone social support and education for adaptation to prostate cancer: a pilot study. Oncology Nursing Forum 31: 335-338.

Seymour Smith S. (2008) 'Blokes don't like that sort of thing': men's negotiation of a 'troubled’ self-help group identity. Journal of Health Psychology 13: 785-797.

Siefert M.L., Williams A., Dowd M.F., Chapel-Aiken L., McCorkle R. (2008) The caregiving experience in a racially diverse sample of cancer family caregivers. Cancer Nursing; 31: 399407.

Templeton H., Coates V.E. (2004) Evaluation of an evidence-based education package for men with prostate cancer on hormonal manipulation therapy. Patient Education and Counselling 55: 55-61.

Tomich P., Hegleson V.S. (2004) Is finding something good in the bad always good? Benefit finding among women with breast cancer. Health Psychology 23: 16-23.

Weber B.A., Roberts B.L., Resnick M., Deimling G., Zauszniewski J.A., Musil C. (2004) The effect of dyadic intervention on self-efficacy, social support, and depression for men with prostate cancer. Psycho-oncology 13: 47-60.

Weber B.A., Roberts B.L., Yarandi H., Mills T.L., Chumbler N.R., Wajsman Z. (2007) The impact of a dyadic social support on self-efficacy and depression after radical prostatectomy. Journal of Ageing and Health 19: 630-645.

Weber B.A., Sherwill-Navarro P. (2005) Psychosocial consequences of prostate cancer: 30 years of research. Geriatric Nursing 26: 166-175.

Wilt T.J., Paul J., Murdoch M., Nelson D., Nugent S., Rubins H.B. (2001) Educating men about prostate cancer screening: a randomized trial of a mailed pamphlet. Effective Clinical Practice 4: 112-120.

Yost K.J., Eton D.T. (2005) Combining distribution and anchor-based approaches to determine minimally important differences - The FACIT Experience. Evaluation and the Health Professions 28: 172-191.

Zhang A.Y., Strauss G.J., Siminoff L.A. (2007) Effects of combined pelvic floor exercise and a support group on urinary incontinence and quality of life of postprostatectomy patients. Oncology Nursing Forum 34: 47-53.

Zhang A.Y., Strauss G.J., Siminoff L.A. (2006) Intervention of urinary incontinence and quality of life outcome in prostate cancer patients. Journal of Psychosocial Oncology 24: 1730 . 
Figure 1 CONNECT programme

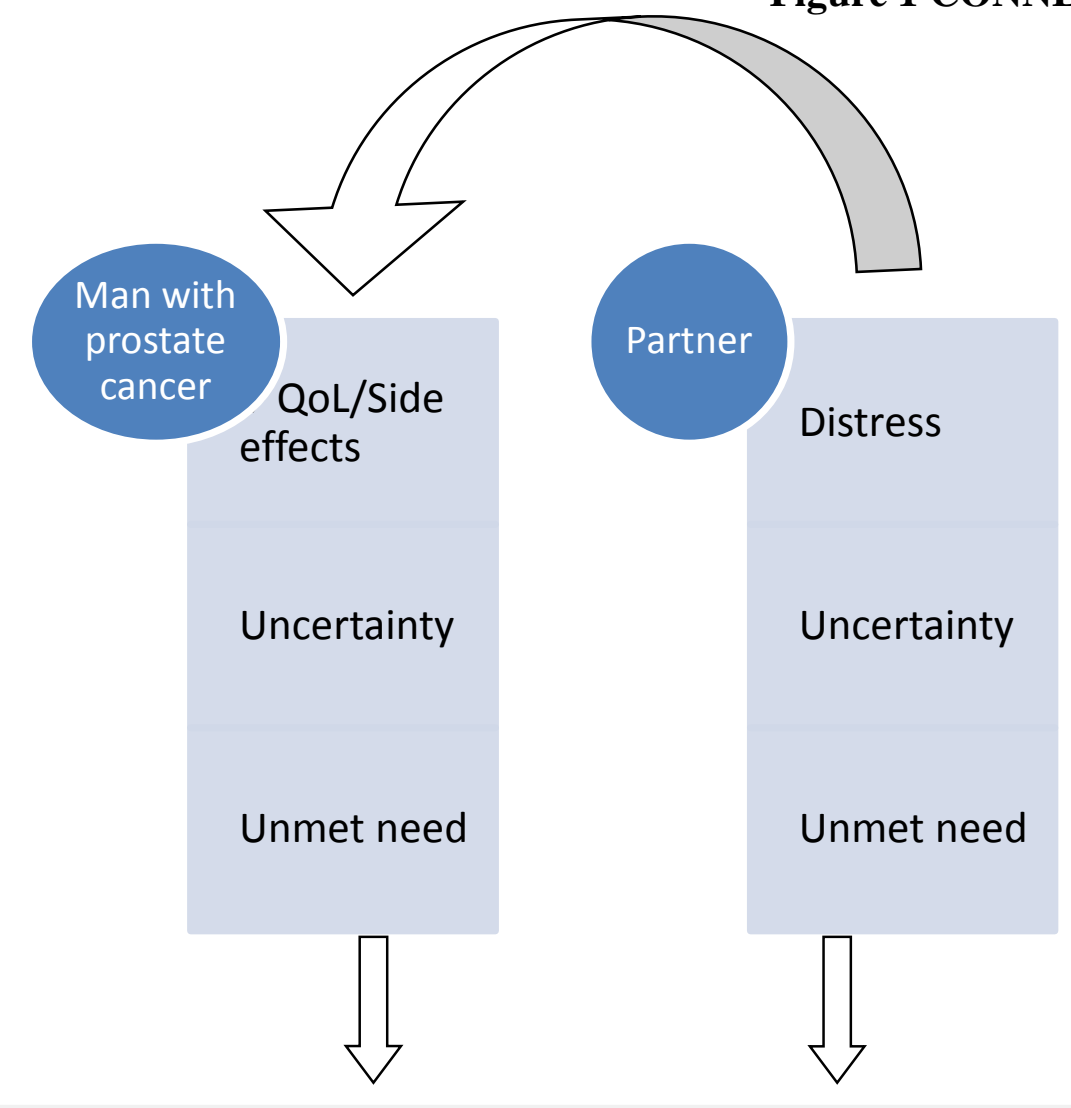

\section{CONNECT PROGRAMME}

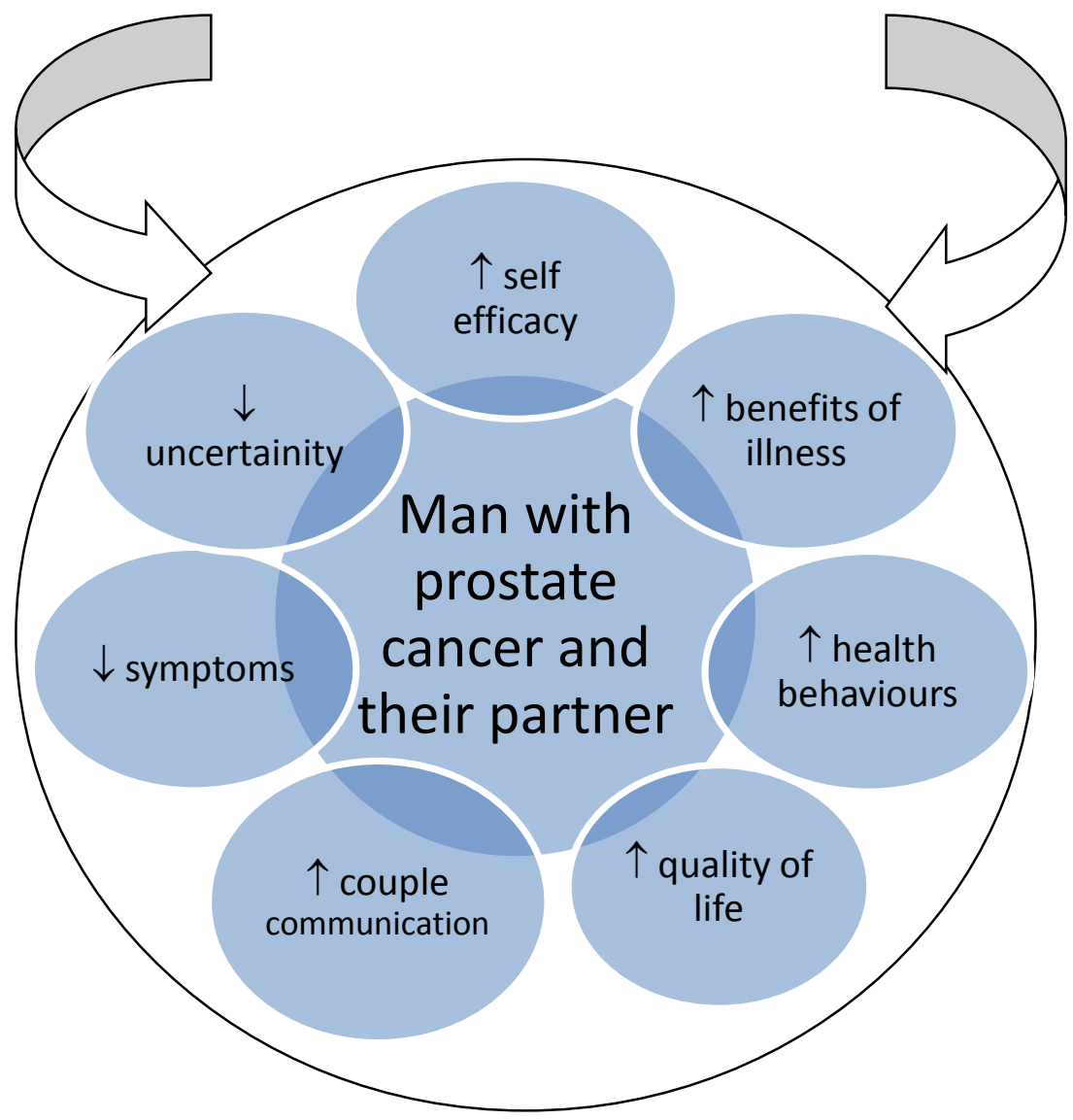


Table 1

Components of CONNECT programme

\begin{tabular}{|l|l|l|l|}
\hline & Component & Aim & Measurement \\
\hline $\mathrm{C}$ & Couple care & $\begin{array}{l}\text { Encourage active involvement of } \\
\text { men and their partners in a planned } \\
\text { programme of care. Develop mutual } \\
\text { support and communication. }\end{array}$ & $\begin{array}{l}\text { Mutuality in Illness Scale } \\
\text { Support Scale } \\
\text { Caregiver Assessment Scale }\end{array}$ \\
\hline $\mathrm{O}$ & $\begin{array}{l}\text { Optimistic } \\
\text { Outlook }\end{array}$ & $\begin{array}{l}\text { Assist men and their partners to } \\
\text { maintain a positive outlook as they } \\
\text { live with the illness and consider } \\
\text { their future. }\end{array}$ & Benefits in Illness Scale \\
\hline $\mathrm{N}$ & $\begin{array}{l}\text { Nourney } \\
\text { Now }\end{array}$ & $\begin{array}{l}\text { Assist men and their partners to } \\
\text { obtain information that will reduce } \\
\text { their uncertainty about the illness } \\
\text { and/or treatments. }\end{array}$ & Uncertainty in Illness Scale \\
\hline $\mathrm{T}$ & $\begin{array}{l}\text { Teach men and their partner's ways } \\
\text { to manage reactions and side effects } \\
\text { associated with the illness, } \\
\text { treatment and adjustment. }\end{array}$ & $\begin{array}{l}\text { Functional Assessment of } \\
\text { Cancer Therapy } \\
\text { Symptom Scale of Omeaga } \\
\text { Screening Questionnaire }\end{array}$ \\
\hline $\mathrm{C}$ & $\begin{array}{l}\text { Empowering } \\
\text { Self }\end{array}$ & $\begin{array}{l}\text { Facilitate men and their partners to } \\
\text { become effective self-managers. } \\
\text { Underpins the intervention. }\end{array}$ & Cancer Self Efficacy Scale \\
\hline Lifestyle & $\begin{array}{l}\text { Encourage men and their partners to } \\
\text { adopt or maintain healthy living } \\
\text { strategies. }\end{array}$ & $\begin{array}{l}\text { Assist men and their partners to set } \\
\text { personal targets in relation to their } \\
\text { illness, treatment and adjustment. } \\
\text { Opportunity to tailor/individualise } \\
\text { the intervention. }\end{array}$ & Health Behaviours Scale \\
Individualised assessment
\end{tabular}


Table 2

Programme Outline

\begin{tabular}{|c|c|c|c|c|c|c|c|}
\hline Group 1 & $\begin{array}{l}\text { Introduction } \\
\text { Purpose of } \\
\text { CONNECT } \\
\text { programme } \\
\text { Meeting times, } \\
\text { location. } \\
\text { Introductions }\end{array}$ & $\begin{array}{l}\text { Couple Care } \\
\text { Partner } \\
\text { involvement in } \\
\text { care. } \\
\text { Mutual support } \\
\text { and } \\
\text { communication }\end{array}$ & $\begin{array}{l}\text { New Normality } \\
\text { Symptom } \\
\text { management } \\
\text { (fatigue, } \\
\text { incontinence, } \\
\text { emotional } \\
\text { reactions, } \\
\text { hormone } \\
\text { treatment) }\end{array}$ & & & & \\
\hline Telephone 1 & & & & & $\begin{array}{l}\text { Target Setting } \\
\text { Self-management } \\
\text { plan }\end{array}$ & & \\
\hline Telephone 2 & & & & & $\begin{array}{l}\text { Target Setting } \\
\text { Review plan and } \\
\text { make alterations }\end{array}$ & & \\
\hline
\end{tabular}


Figure 2 CONNECT flow chart

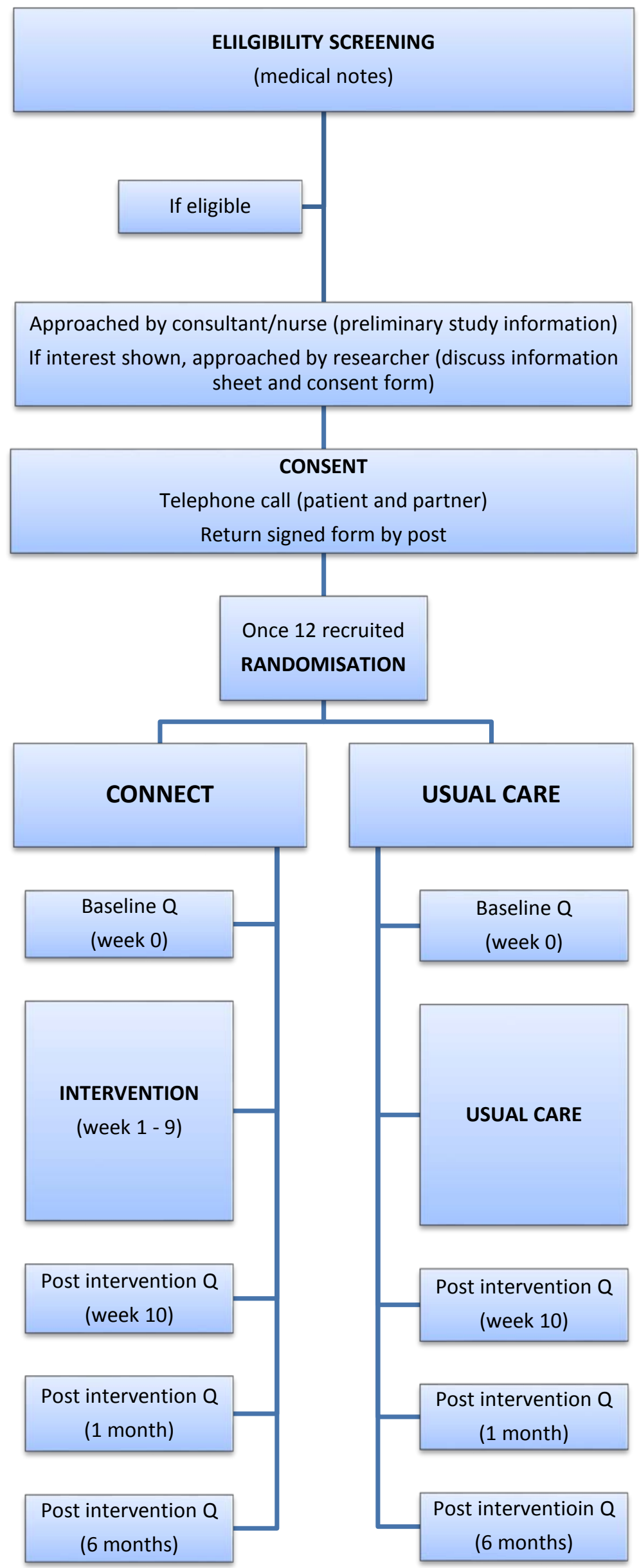


